\title{
Fashion Revolution Day Porto Alegre: cenário e motivaçōes de mudanças
}

\author{
Fashion Revolution Day Porto Alegre: current scenario and motivations \\ for future change
}

NEUMANN, Daniela

Universidade Federal do Rio Grande do Sul - UFRGS I danineumannd@gmail.com

MOREIRA, Andréa

Universidade Federal do Rio Grande do Sul - UFRGS I andreamoreira@outlook.com

GIONGO, Marina

Universidade Federal do Rio Grande do Sul - UFRGS I marinagiongo@gmail.com

RÜTHSCHILLING, Evelise A.

Universidade Federal do Rio Grande do Sul - UFRGS I anicet@ufrgs.br

JACQUES, Jocelise

Universidade Federal do Rio Grande do Sul - UFRGS I jocelise.jacques@ufrgs.br

\section{Resumo \\ O desenvolvimento sustentável é um grande desafio \\ Abstract} para a moda, que vem sendo cada vez mais observado e debatido no campo. Diante disso, este artigo tem como objetivo, apresentar e discutir os dados coletados a partir de depoimentos de participantes do Fashion Revolution Day Porto Alegre 2017, para verificar a repercussão do discurso do movimento nos participantes do evento. Para realização da pesquisa foram estabelecidos oito parâmetros que nortearam a análise de conteúdo. Por meio deste estudo, buscou-se compreender o entendimento do público participante a respeito do evento e suas expectativas. Espera-se que a análise contribua para entender a influência do movimento junto ao público presente e auxilie no planejamento dos próximos eventos e novas ações que atinjam um maior número de pessoas, abrangendo um público ainda distante da visão do movimento. O estudo intenciona, ainda, promover uma indústria de moda que valorize em um mesmo patamar as pessoas, o meio-ambiente, a criatividade e o lucro.

Palavras Chave: Fashion Revolution. Indústria da moda. Moda ética.
A major challenge for the fashion industry is the sustainable development, which has been in the center of current discussions in the field. In this context, this paper aims to present and discuss data collected from interviews with participants of Fashion Revolution Day Porto Alegre 2017, in order to investigate the repercussion of the sustainable ideas among them. The research and the content analysis were supported by eight parameters. Our primary focus was to assess the participants understanding about the event and their expectations. Hopefully, data presented in this study will reveal the level of awareness among the audience and assist the planning of upcoming events. It might as well encourage new approaches to reach a larger audience, including the ones unaware of the sustainable speech. This study intends to support, at the same level, a fashion industry that values people, natural environment, creativity and profit.

Keywords: Fashion revolution. Fashion industry. Ethical fashion. 


\section{INTRODUC̣ÃO}

A indústria de moda e vestuário é um setor expressivo para a economia mundial, estimado em US\$2,4 trilhões (MCKINSEY COMPANY, 2017) e com perspectiva de crescimento de $2,5 \%$ na produção de vestuário, $4 \%$ na produção têxtil e de $5 \%$ no varejo de vestuário. Com isto, prevê um faturamento de $R \$ 152$ bilhões e investimento de R\$2,25 milhões para o ano de 2018 (ASSOCIAÇÃO BRASILEIRA DA INDÚSTRIA TÊXTIL E DE CONFECÇÃO, 2017a). No Brasil, o setor têxtil é o segundo maior empregador, sendo superado apenas pelo setor de alimentos e bebidas. Possui 1,7 milhões de colaboradores diretos, dos quais 75\% são mão-de-obra feminina. Sendo assim, a indústria têxtil representa 16,4\% dos empregos e 5,5\% do faturamento da indústria de transformação brasileira (ASSOCIAÇÃO BRASILEIRA DA INDÚSTRIA TÊXTIL E DE CONFECÇÃO, 2017b).

Segundo a Associação Brasileira da Indústria Têxtil e de Confecção - ABIT, o Brasil é a última cadeia têxtil completa do ocidente, apresentando autossuficiência na produção desde o algodão até a fibra, passando pelos processos de fiação, tecelagem, beneficiadoras, confecções, até alcançar os desfiles de moda e o varejo. A produção anual de peças confeccionadas é de 9,4 bilhões, das quais 5,3 bilhões são peças de vestuário, tendo como referência os mercados de moda praia e jeans (ASSOCIAÇÃO BRASILEIRA DA INDÚSTRIA TÊXTIL E DE CONFECÇÃO, 2017b). "A indústria de confecção absorve todos os produtos finais dos elos anteriores para a transformação em produtos confeccionados destinados ao consumidor final" (ALENCAR et al., 2015, p. 3). Os números do mercado brasileiro refletem o poder da indústria no país e a capacidade que tem de gerar impacto social e ambiental, seja este positivo ou negativo.

O Fashion Revolution é um dos movimentos que contestam a forma como são produzidos e consumidos os produtos de moda atualmente, buscando questionar o sistema e conscientizar os consumidores (NUNES; ROCHA, 2015). Formado por um conselho global de líderes da moda sustentável, acadêmicos ativistas e imprensa, o movimento tem como principal objetivo trazer à tona os verdadeiros custos da produção de peças de vestuário. Visa, desta forma, conscientizar o consumidor a ser protagonista em seu processo de consumo e questionar as marcas que veste em relação à responsabilidade social e ambiental (FASHION REVOLUTION BRASIL, 2017; SILVA; CANDIDO, 2016).

O Fashion Revolution Day é uma ação para a promoção da moda sustentável, proposta pelo movimento, que surgiu após o desabamento do edifício Rana Plaza em Bangladesh no ano de 2013, evento que deixou 1.133 mortos e 2.500 feridos. A mobilização surgiu em Londres, tendo por fundadoras as ativistas e designers, Carry Somers e Orsola de Castro, com o principal objetivo de aumentar a conscientização sobre o verdadeiro custo da 
moda e seu impacto em todas as fases do processo de produção e consumo. Propõe-se, dessa forma, a mostrar ao mundo que a mudança é possível por meio do engajamento dos envolvidos na criação de um futuro mais sustentável, criando conexões e exigindo transparência na indústria da moda (FASHION REVOLUTION BRASIL, 2017).

O Fashion Revolution Week, evento que abrange o Fashion Revolution Day, estendendo a uma semana a realização de atividades vinculadas à questão, envolve ações de ativistas em diversos países, expandindo a cada ano a sua abrangência e contando, em 2017, com a participação de 92 países. O evento ocorre em abril, próximo ao dia 24, data que marca o Fashion Revolution Day, e contempla ações que buscam a conscientização das pessoas em relação aos problemas da cadeia da moda. Uma das propostas é o uso da hashtag \#whomademyclothes (\#quemfezminhasroupas), que incentiva marcas e produtores a responderem à questão, também por meio do uso de hashtags \#imadeyourclothes; (\#eufizsuasroupas) e a tornarem seus processos mais transparentes (FASHION REVOLUTION BRASIL, 2017).

Ao longo do mês de abril, diversas instituições de ensino e mercado promoveram eventos com debates, palestras, oficinas e visitas guiadas a empresas do vestuário. A figura 1 apresenta exemplos dos cards que foram utilizados na divulgação do evento nos anos de 2016 e 2017. Estes cards, que trazem citações, dados e hashtags sobre o tema, foram disponibilizados para que as pessoas pudessem compartilhar em suas redes sociais, a fim de disseminar as informações sobre o movimento.

Figura 1 - Cards disponibilizados pelo Fashion Revolution Brasil.

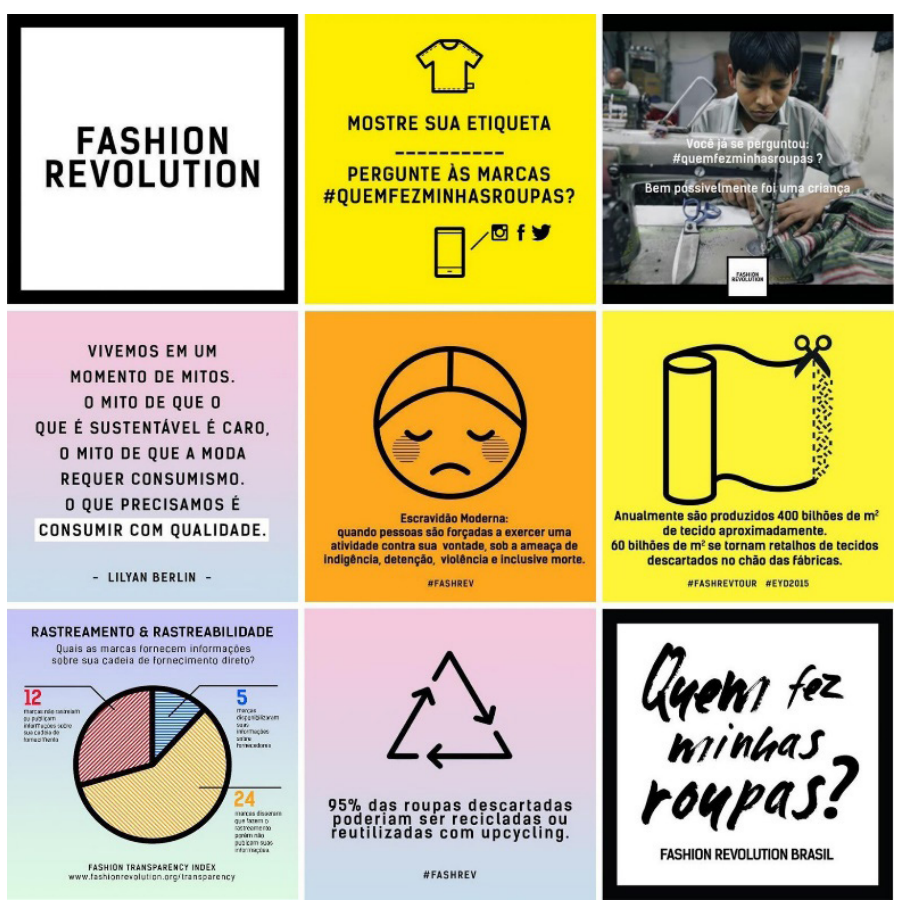

Fonte: Fashion Revolution (2016). 
A relação entre a moda e os princípios de sustentabilidade se tornou mais intensa nas últimas décadas, devido ao grande número de ações com o objetivo de conciliar os interesses de ambos. Para Fletcher e Grose (2011), a sustentabilidade talvez seja a maior crítica que o setor da moda já enfrentou, pois desafia a moda em seus detalhes como, por exemplo, fibras e processos não apenas frente a questões técnicas mas também em relação aos vários aspectos solidários envolvidos: modelos econômicos, metas, regras, sistemas e valores.

Segundo Berlim (2012), para um produto ser sustentável sua matériaprima deve ser derivada de recursos renováveis e deve existir um bom aproveitamento dos recursos não renováveis. Os resíduos gerados devem ser capazes de se "renaturalizar" e cada comunidade deveria produzi-lo com base em seu espaço ambiental, sem invadir o local de outras comunidades. Elkington (1998) pressupõe a existência de três dimensões na sustentabilidade: ambiental, social e econômica. A partir destas, Sachs (2002) propõe o desenvolvimento de oito dimensões da sustentabilidade sendo elas: ambiental, cultural, ecológica, econômica, social, territorial, política nacional e política internacional.

Sustentabilidade não está apenas relacionada a ações de filantropia, gestão de resíduos ou plantio de árvores, mas a uma reorganização de visão de mundo de cada cidadão. É algo que requer uma profunda e íntima reflexão sobre o que é considerado desenvolvimento e para onde este desenvolvimento está levando a humanidade, quais são suas consequências, que preço estamos pagando por ele e como temos nos relacionado com a natureza, da qual fazemos parte (BERLIM, 2012, p. 14).

Nesse contexto, o objetivo deste estudo é apresentar e discutir os dados captados com a realização de uma análise de conteúdo do discurso de participantes do evento Fashion Revolution Day Porto Alegre 2017. A análise deve contribuir para compreender a repercussão do movimento junto ao público participante, a fim de auxiliar o planejamento dos próximos eventos, e a orientação de novas ações que atinjam um maior número de pessoas, alcançando um público que se encontra, ainda distante da visão do movimento. Da mesma forma, espera-se colaborar para a promoção de uma indústria de moda que reconheça em um mesmo patamar as pessoas, o meio-ambiente, a criatividade e o lucro. A seguir serão apresentados os procedimentos metodológicos aplicados, os resultados obtidos e discussões a respeito da análise realizada. 


\section{PROCEDIMENTOS METODOLÓGICOS}

Esta é uma pesquisa de cunho qualitativo, elaborada por acadêmicas do Programa de Pós-Graduação em Design da Universidade Federal do Rio Grande do Sul - PGDesign/UFRGS, durante o evento Fashion Revolution Day Porto Alegre 2017, realizado com apoio do Núcleo de Moda Sustentável NDS/UFRGS. Para o seu desenvolvimento, foram coletados depoimentos de participantes presentes no evento, registrados em formato de áudio e vídeo. Os dados reunidos foram averiguados por meio de análise de conteúdo.

De acordo com Bardin (2016), a análise de conteúdo se configura em um conjunto de instrumentos e técnicas metodológicas que se aperfeiçoam constantemente, podendo ser aplicados a discursos e conteúdos bastante diversificados. A análise de conteúdo enfatiza as mensagens e comunicações, podendo ser definida por uma categoria ou temática. Tem por objetivo a manipulação das mensagens do discurso para confirmação de indicadores que permitem inferir sobre diferentes realidades (BARDIN, 2016).

A análise de conteúdo se organiza em três etapas: pré-análise, exploração do material e tratamento dos resultados (BARDIN, 2016). Na fase de pré-análise foi realizada uma pesquisa documental, a partir dos materiais disponibilizados pelo Fashion Revolution, para a compreensão do conteúdo a respeito do movimento que é proposto pelos próprios ativistas e os parâmetros de moda sustentável envolvidos nesta pesquisa. A partir deste estudo inicial, foram elaboradas as questões que nortearam a elaboração dos mecanismos de coleta e dos testemunhos dos participantes.

Os participantes foram convidados a colaborar com a sua opinião a partir da proposição de duas questões. Na fase de exploração do material, os depoimentos foram transcritos e os dados analisados com base em oito parâmetros de análise pré-definidos, que serão explicitados no próximo tópico. Ao longo da última etapa, os dados foram tratados e organizados em gráficos e figuras para auxiliar na compreensão dos resultados, visando uma melhor identificação dos parâmetros mais recorrentes observados nos depoimentos.

\subsection{Coleta de Dados}

A coleta de dados desta pesquisa foi executada durante o Fashion Revolution Day POA 2017, evento realizado no Santander Cultural, pela equipe Fashion Revolution Porto Alegre e com apoio do Núcleo de Moda Sustentável da Universidade Federal do Rio Grande do Sul - UFRGS'. A utilização destes 
dados na investigação é possível de acordo com a resolução 510/2016 do Conselho Nacional de Saúde - CONEP (BRASIL. 2016), que determina que dados emergentes de situações de trabalho podem ser utilizados desde que não identifiquem os participantes. Foram coletados depoimentos de 13 pessoas, que participaram do evento e assinaram o termo de liberação de imagem, pois as falas foram registradas em vídeo e áudio. Os depoimentos foram feitos com base nas seguintes perguntas:

\section{a. $\mathbf{O}$ que você entende sobre o Fashion Revolution? \\ b. $\quad 0$ que você espera do evento?}

Para oportunizar a comparação dos dados, também foram utilizadas as informações coletadas via formulário de inscrição do evento, onde os mesmos participantes responderam em dois campos separados as questões c) e d).

\section{c. O que é o Fashion Revolution para você? \\ d. Como você faz parte da revolução da moda? Como você se relaciona com a moda ética e sustentável?}

Na etapa de análise das respostas, constatou-se que as questões do formulário de inscrição provocaram resultados mais reflexivos em relação às próprias atitudes e convicções dos participantes, enquanto as perguntas realizadas durante a entrevista ofereceram respostas mais voltadas ao movimento e seus reflexos na sociedade. Considera-se possível que o modo como as perguntas foram apresentadas aos participantes possam ter sido responsáveis por induzir esta diferença nos discursos.

\subsection{Perfil da Amostra}

Participaram da coleta 13 mulheres; inscritas e presentes no dia do evento; graduadas ou estudantes de nível superior; com atuação nas áreas de: design (de moda, têxtil e generalista), jornalismo e empreendedorismo; residentes em Porto Alegre e região metropolitana. Para realizar a análise de conteúdo, foram estabelecidos dois critérios de seleção dos depoimentos: (1) participantes com formulário de inscrição preenchido corretamente e (2) qualidade do áudio do depoimento. Com a aplicação dos parâmetros, foram selecionados 10 depoimentos para a realização da análise.

\subsection{Parâmetros Adotados para a Análise}

Para realizar a análise de conteúdo foram definidos oito parâmetros, estabelecidos por meio de uma análise preliminar do conteúdo dos cards materiais de comunicação disponibilizados pelo Fashion Revolution em seus 
canais online. Nesta análise identificaram-se oito ideias recorrentes no discurso do movimento. Os parâmetros de análise foram delimitados da seguinte forma:

[1] ativismo; [2] moda ambientalmente amigável - dimensão ambiental; [3] moda ética - dimensão social; [4] consumo consciente; [5] transparência; [6] importância do movimento Fashion Revolution; [7] conhecimento de mercado em moda sustentável [8] conhecimento acadêmico em moda sustentável. A seguir, esses aspectos de análise serão descritos para o entendimento dos fatores que foram considerados durante a análise de conteúdo.

O parâmetro ativismo refere-se à tomada de ações para catalisar, encorajar e promover a mudança, a fim de suscitar transformações sociais, culturais e/ou políticas, envolvendo também, a transformação dos ativistas, de maneira individual (FUAD-LUKE, 2013). De acordo com a pesquisa de Machado (2007), a maioria destas ações se relaciona com quatro formas de ativismo: tensão política; protesto e guerra digital; protesto antiglobalização ou anticapitalismo; e ativismo ecológico e em prol dos direitos humanos. O movimento Fashion Revolution perpassa as ações propostas por Fuad-Luke (2013), ao promover a mudança na indústria da moda, principalmente por meio de protesto digital, protesto anticapitalismo e ativismo ambiental e em prol dos direitos dos trabalhadores do setor.

O quesito moda ambientalmente amigável - dimensão ambiental se relaciona com a busca dos estilistas por inserir a sustentabilidade na moda de diferentes maneiras. Entre os exemplos estão aqueles profissionais que defendem causas sociais e ambientais, investem em pesquisas de novos materiais naturais e renováveis para serem utilizados em suas coleções, aproveitam sobras de tecidos e se recusam a usar couro e pele de animais em extinção. Grandes e pequenas empresas reavaliam seus processos e produtos e, as mais avançadas, não apenas realizam essas mudanças de maneira pontual, em coleções isoladas, mas as incorporam em suas estratégias de maneira definitiva.

Algumas marcas de moda, em paralelo, preferem trabalhar com técnicas tradicionais de confecção como, por exemplo, o artesanato, visando beneficiar comunidades com projetos de geração de renda, criar produtos com tecidos e design inovadores e valorizar a cultura e os materiais locais (UNIETHOS, 2013). Esse viés é observado como um modelo de abordagem que busca melhorias no processo e cadeia envolvida no sistema produtivo, sendo também contemplado como estratégia para a moda ética.

O parâmetro da moda ética - dimensão social se concentra na saúde dos consumidores e nas condições de trabalho das pessoas envolvidas na indústria da moda. A ênfase recai tanto sobre o aspecto ambiental como o aspecto social (SALCEDO, 2014). A moda ética representa uma abordagem de pesquisa, design e produção de roupas que aumenta os benefícios para as comunidades e pessoas de forma a minimizar o impacto no meio ambiente. Representa 
uma busca ativa da redução da pobreza e da diminuição de impactos sociais e ambientais, por meio do desenvolvimento sustentável (ETHICAL FASHION FORUM, 2017).

O consumo consciente é a transformação do ato de compra e consumo em atos de cidadania, que se consolida no momento em que as pessoas passam a optar preferencialmente por produtos, serviços e empresas que contribuam para uma condição de vida ambientalmente sustentável e socialmente justa (INSTITUTO AKATU, 2017). Repensar o consumo de moda é ir além do produto, sua produção e seu ciclo de vida. Contempla também o gerenciamento da obsolescência, não apenas pelo desgaste da peça, mas aquela que é motivada pela aparência e pelos ciclos da moda, condicionando o fim da vida de alguns produtos enquanto suas funções ainda permanecem válidas (KAZAZIAN, 2005). O usuário, tendo cuidado com seu consumo, poderá comunicar que é um indivíduo consciente, que tem uma preocupação com as gerações futuras e a preservação do planeta. Afinal, a moda comunica, o vestuário fala e o consumidor torna-se o elo de ligação que transmite a mensagem.

A transparência refere-se ao conhecimento e a disponibilização de informações acerca das etapas que compõem a cadeia produtiva na indústria da moda, possibilitando ao consumidor fazer as suas escolhas de maneira consciente. Trabalhar de forma transparente implica abertura, comunicação e responsabilidade (FASHION REVOLUTION, 2016).

A importância do movimento Fashion Revolution está relacionada ao fato de o evento ser considerado uma campanha global que pede transparência, ética e sustentabilidade na indústria da moda. O dia 24 de abril relembra a tragédia de grande impacto do Rana Plaza e é a data oficial do Fashion Revolution Day. Durante a semana que contém esta data, vários eventos no mundo todo são realizados, sendo crescente o número de cidades participantes no movimento. No ano de 2017, entre os dias 24 e 30 de abril mais de 90 países estiveram fazendo parte das campanhas de divulgação do evento (FASHION REVOLUTION BRASIL, 2017).

O parâmetro de análise conhecimento de mercado em moda sustentável diz respeito ao interesse do público em geral em compreender o mercado de moda sobre o viés da sustentabilidade ampliando assim, a sua visão a respeito do assunto. Esse processo resulta em ações relevantes voltadas para a sustentabilidade como, por exemplo, investimentos em novos materiais e fibras, a valorização do design e o incentivo tecnológico, desde a engenharia de produção e logística, até o produto final, bem como a identificação dos anseios dos consumidores e das tendências (VALENTE, 2012).

O último parâmetro analisado é o conhecimento acadêmico em moda sustentável. Este quesito revela-se necessário, visto que o designer geralmente lidera o desenvolvimento de uma coleção, sendo responsável por grande parte 
das decisões a serem tomadas durante todo o processo de criação. Deste modo, o designer que deseja projetar guiado pelos princípios da sustentabilidade precisa levar em consideração o contexto no qual o projeto está inserido, conciliando interesses da sociedade, do meio ambiente e da economia. Gerenciar essas três dimensões de modo responsável e adotar uma abordagem holística torna-se um grande desafio no desenvolvimento de produtos (GWILT, 2014).

Por esse motivo, a academia possui um importante papel enquanto promotora de uma mudança de paradigmas na moda, atuando como um laboratório de experimentos sustentáveis (CAMARGO; RÜTHSCHILLING, 2016). A partir do desenvolvimento e cultivo do pensamento reflexivo e crítico, torna-se capaz de estimular os estudantes, ao longo de toda a sua formação, e os profissionais da moda atuantes no mercado a agirem de forma mais ética, responsável e sustentável.

\section{APRESENTAC̣ÃO E DISCUSSÃO DOS RESULTADOS}

Durante a coleta de dados, foi observado entre o público participante, o interesse em compreender melhor, principalmente o parâmetro conhecimento de mercado em moda sustentável, demonstrando isso em seus depoimentos. A análise preliminar do conteúdo, também identificou o interesse dos participantes do evento na importância do movimento Fashion Revolution para a moda sustentável, visto que é um movimento global presente em 92 países. A visibilidade internacional do movimento foi um ponto motivador para alguns participantes.

O escalonamento dos dados resultante da análise de conteúdo, conforme visto no Quadro 1, permite a realização de uma observação da percepção do público sobre o movimento em dois níveis: individual e coletivo. Observando os resultados de pontuação conferida para cada parâmetro e considerando o somatório destas pontuações, entre todos os entrevistados da amostra, é possível verificar a relevância de determinados parâmetros.

Com base no gráfico 1, é possível identificar que os parâmetros de análise

2 e 4 - moda ambientalmente amigável - dimensão ambiental e consumo consciente, respectivamente - foram assuntos mais comentados e destacados. Somam-se a estes, em sequência, os parâmetros de análise $\mathbf{3}$ e $\mathbf{6}$ - moda ética dimensão social e a importância do movimento Fashion Revolution - enquanto os demais aspectos de análise que obtiveram uma pontuação acima da média (aproximadamente 6) na percepção geral da amostra.

Os parâmetros 7 e 8 - conhecimento de mercado em moda sustentável e conhecimento acadêmico em moda sustentável obtiveram o mesmo somatório de maneira coletiva, evidenciando a importância destes dois quesitos estarem 
Quadro 1 - Escalonamento dos dados da análise de conteúdo.

\begin{tabular}{|c|c|c|c|c|c|c|c|c|c|}
\hline \multirow{5}{*}{ PARÂMETROS } & [ 1 ] ATIVISMO & \multicolumn{8}{|c|}{ [ 2 ] MODA AMBIENTALMENTE AMIGÁVEL-DIMENSÃO AMBIENTAL } \\
\hline & \multicolumn{4}{|c|}{ [ 3 ] MODA ÉTICA - DIMENSÃO SOCIAL } & \multicolumn{5}{|c|}{ [ 4] CONSUMO CONSCIENTE } \\
\hline & [ 5 ] TRANSPARÊNCIA & \multicolumn{8}{|c|}{ [ 6 ] IMPORTÂNCIA DO MOVIMENTO FASHION REVOLUTION } \\
\hline & \multicolumn{9}{|c|}{ [ 7 ] CONHECIMENTO DE MERCADO EM MODA SUSTENTÁVEL } \\
\hline & \multicolumn{9}{|c|}{ [ 8 ] CONHECIMENTO ACADÊMICO EM MODA SUSTENTÁVEL } \\
\hline ENTREVISTADOS & OCUPAÇÃO & [1] & [ 2 ] & [3 ] & [4] & [5] & [6] & [7] & [8] \\
\hline ENTREVISTADO 01 & DESIGNER & 1 & 1 & 1 & 2 & 0 & 0 & 1 & 1 \\
\hline ENTREVISTADO 02 & DESIGNER & 0 & 1 & 2 & 2 & 0 & 1 & 1 & 1 \\
\hline ENTREVISTADO 03 & ESTUDANTE & 0 & 1 & 0 & 2 & 0 & 1 & 0 & 0 \\
\hline ENTREVISTADO 04 & JORNALISTA & 0 & 2 & 1 & 1 & 1 & 2 & 0 & 0 \\
\hline ENTREVISTADO 05 & DOCENTE & 1 & 2 & 0 & 0 & 0 & 0 & 0 & 0 \\
\hline ENTREVISTADO 06 & ESTUDANTE & 1 & 2 & 2 & 1 & 0 & 1 & 1 & 0 \\
\hline ENTREVISTADO 07 & DESIGNER/DOCENTE & 0 & 0 & 0 & 1 & 0 & 0 & 0 & 1 \\
\hline ENTREVISTADO 08 & DESIGNER DE MODA & 2 & 1 & 0 & 1 & 0 & 2 & 0 & 0 \\
\hline ENTREVISTADO 09 & DESIGNER TÊXTIL & 1 & 0 & 0 & 2 & 0 & 1 & 1 & 1 \\
\hline ENTREVISTADO 10 & ESTILISTA & 0 & 0 & 1 & 0 & 1 & 0 & 1 & 1 \\
\hline & SOMATÓRIO & 6 & 10 & 7 & 12 & 2 & 8 & 5 & 5 \\
\hline
\end{tabular}

Fonte: elaborado pelas autoras com base na coleta de dados.

Gráfico 1 - Percepção geral dos parâmetros analisados.

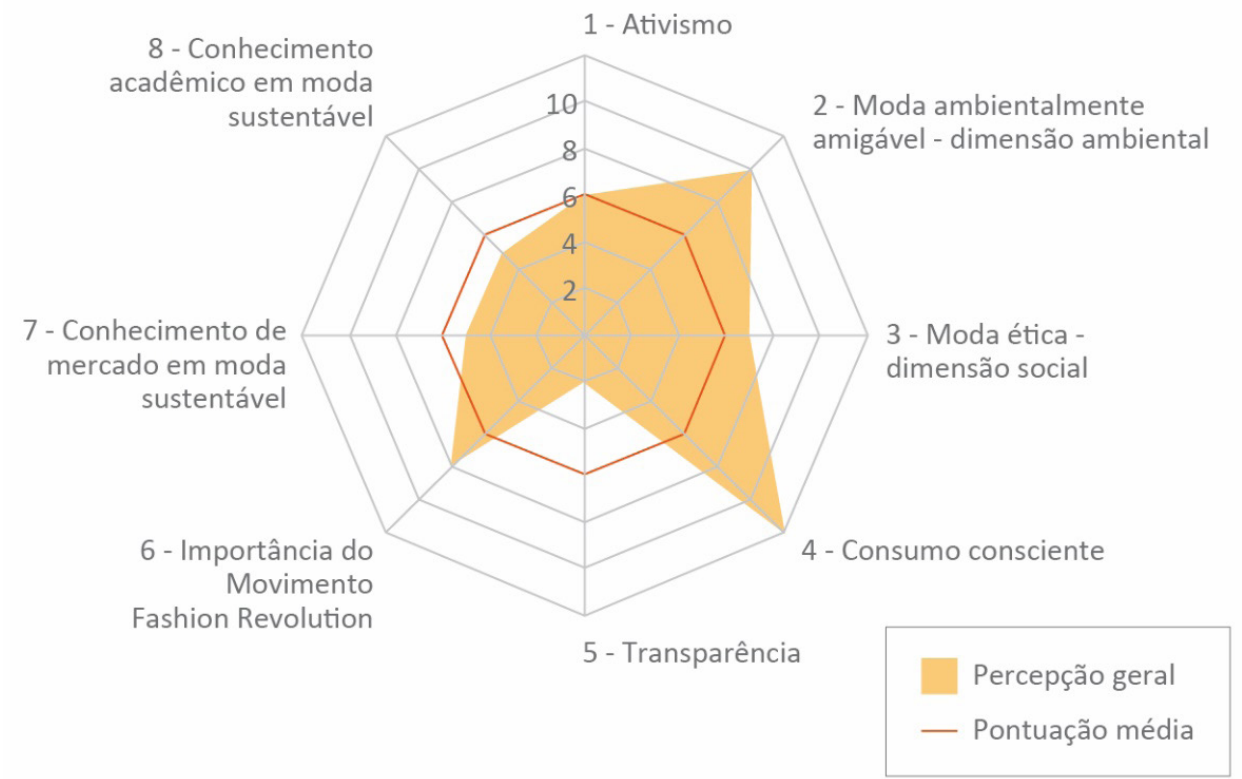

Fonte: elaborado pelas autoras com base na coleta de dados.

alinhados, para fomentar a cultura da sustentabilidade no âmbito acadêmico e possuírem um reflexo significativo no setor mercadológico, principalmente na produção de produtos de moda mais sustentáveis. O parâmetro 5 transparência na indústria da moda foi o menos pontuado, demonstrando 
que ainda existe pouco conhecimento e informação sendo divulgados sobre as etapas que integram a cadeia produtiva de moda. Ou seja, a maior parte das empresas trabalham de forma limitada a sua transparência, revelando pouca comunicação e responsabilidade para com a sociedade e o meio ambiente, ainda tendo o lucro como objetivo principal.

Ao considerar as pontuações dos parâmetros de análise observados, em cada depoimento de forma individual, é possível ainda verificar a relevância de cada parâmetro na percepção particular dos entrevistados. Conforme demonstrado no gráfico 2 , foi feita a comparação da recorrência das menções dos assuntos por um mesmo indivíduo nos diferentes momentos de coleta de dados.

Nesta análise, os parâmetros de análise 1 - ativismo, 2 - moda ambientalmente amigável-dimensão ambiental, 3-modaética-dimensão social, 4 - consumo consciente e 6 - importância do movimento Fashion Revolution sobressaem-se aos demais com igual importância, sendo interessante destacar como diferencial frente à análise geral, o surgimento do parâmetro 1 - ativismo, dentre os mais relevantes na percepção individual.

Gráfico 2 - Percepção e comparação individual dos parâmetros analisados.
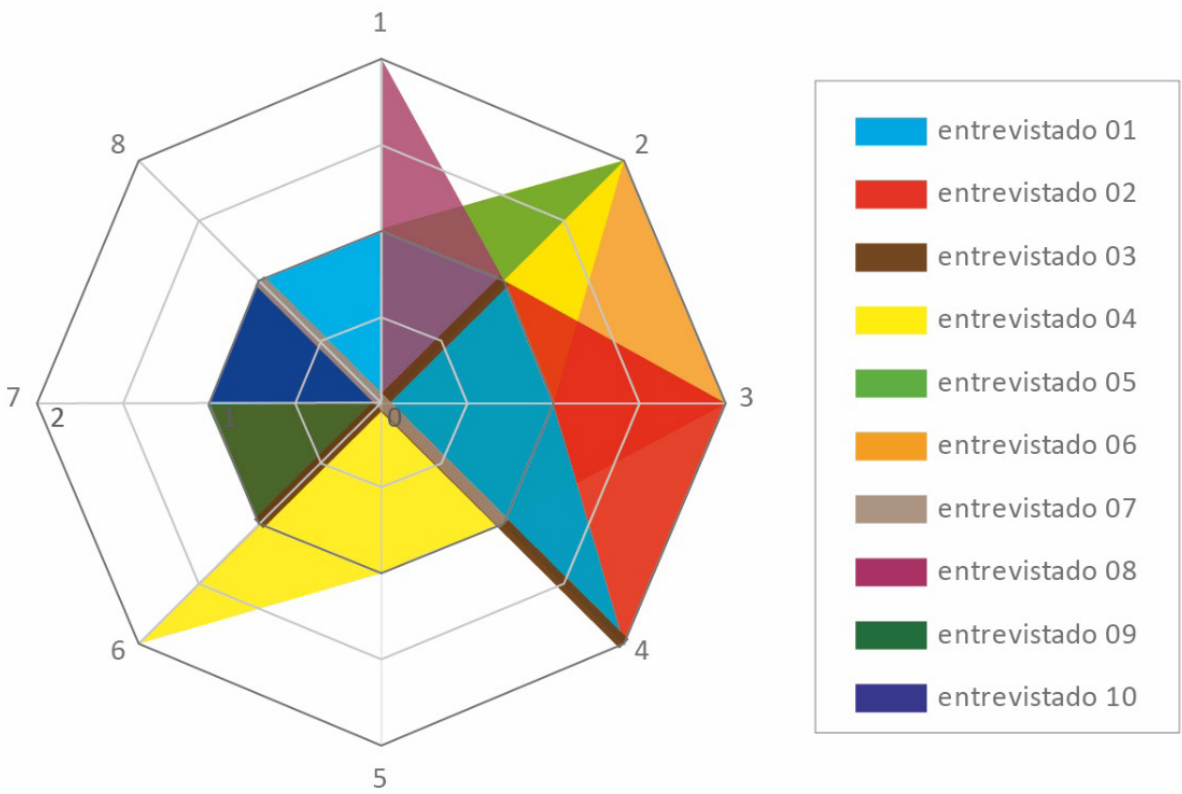

Fonte: elaborado pelas autoras com base na coleta de dados.

Entende-se, de forma geral, o sucesso da comunicação do Fashion Revolution no debate com os seus participantes, principalmente, de forma individual e coletiva, nos seguintes parâmetros: $\mathbf{2}$ - moda ambientalmente amigável - dimensão ambiental, 3 - moda ética - dimensão ambiental e 4 consumo consciente.

Em ambos os níveis de análise, individual e coletivo, entretanto, o parâmetro 5, que questionava a transparência das marcas e do mercado - 
obteve uma pontuação significativamente baixa em relação aos demais. Esse resultado sugere a existência de uma lacuna na comunicação do movimento para com o público do evento, assim como se distancia da indústria da moda, em que a transparência e responsabilidade ainda são princípios pouco trabalhados.

\subsection{Declarações Relevantes}

No discurso dos respondentes, por diversas vezes foram identificados mais de um critério de análise. Nestes casos, foi considerada a ideia mais presente em cada declaração. Na Figura 3, estão apresentadas as principais declarações e ideias presentes no discurso dos entrevistados, para cada um dos parâmetros de análise.

Quadro 2 - Declarações relevantes para cada critério de análise.

PARÂMETROS

[1] ATIVISMO

[ 2 ] MODA
AMBIENTAL
AMIGÁVEL
- DIMENSÃO
AMBIENTAL

\section{[ 3 ] MODA ÉTICA - DIMENSÃ̃O SOCIAL}

[ 4 ] CONSUMO CONSCIENTE

[5] TRANSPARÊNCIA

[ 6 ] IMPORTÂNCIA DO MOVIMENTO FASHION REVOLUTION

[ 7 ] CONHECIMENTO DO MERCADO EM MODA SUSTENTÁVEL

[8] CONHECIMENTO ACADÊMICO EM MODA SUSTENTÁVEL

\section{DECLARAÇõES}

E6: "Unidos iremos mudar o modo como a moda funciona hoje".

E8: "Estou envolvida no projeto moda na comunidade".

E8: "Agregar e passar isso para o consumidor".

E4: "Atuo em minha empresa defendendo, organizando e comunicando os movimentos e designers que trabalham de forma ética e sustentável no RS".

E5: "Debate aprofundado sobre essa questão de uma moda bastante poluidora

[...] considerando o futuro das próximas gerações".

E6: "Fazer projetos na faculdade voltados para a sustentabilidade".

E8: "Produzir uma moda limpa do início ao fim".

E1: "Projetar a partir de preceitos sustentáveis, evitando a agressão do meio ambiente e das pessoas que dele fazem parte".

E6: "Como designer pesquiso e volto meu trabalho em busca do produto que não pense só no meio ambiente, mas também na sociedade".

E10: "Utilizar de forma correta todos os materiais [...] modelos executados manualmente, com ligação com os clientes".

E1: "É um grande ato de conscientização até mesmo para quem não tem interesse por moda".

E1: "Boicoto marcas exploradoras".

E2: "Dou preferência para produtos sustentáveis ou com apelo social".

E3: "Melhorar o próprio consumo ou até diminuir ele parte muito de uma autoconsciência".

E3: "Eu comecei a avaliar as minhas decisões de compra".

E6: "Busco cada dia mais refletir sobre o meu consumo".

E7: "Sendo uma consumidora mais exigente e investigativa".

E7: "Comprar de forma inteligente, menos é mais".

E8: "Fazer com que as pessoas se questionem cada vez mais a procedência do que consomem e apoiam".

E4: "Passar a informação do que se trata e de como funciona de verdade a cadeia da moda, que a maioria das pessoas desconhece".

E10: "Clientes ficam conhecendo todas as etapas do processo de criação das peças".

E2: "Fashion Revolution é um evento produzido por pessoas incríveis que querem muito conscientizar a população sobre moda sustentável".

E3: "Que mude um pouquinho a visão de cada um".

E4: "Primeiro movimento a chamar atenção globalmente, e de forma organizada, para a (in)sustentabilidade da moda".

E6: "Mostrar pro o mundo os impactos que a moda tá causando no meio ambiente e socialmente".

E9: "O Fashion Revolution é um ativismo que pode revolucionar o cenário de consumo de moda".

E1: "Conhecer coisas diferentes daqui que eu não conheço ainda".

E2: "Conhecer outras marcas, outras visões, ver o que as pessoas estão pensando".

E6: "Que o pessoal possa abrir a cabeça para novas possibilidades".

E9: "Conhecer as marcas, como elas estão inseridas neste movimento,

o que elas produzem, com que objetivo".

E1: "Conhecer novas pessoas que estão começando a trabalhar e pensar nisso".

E7: "Abrindo espaço para debates e busca de soluções em sala e aula".

E10: "Agregar cada vez mais conhecimento, porque quanto mais a gente

pesquisa e se informa sobre o assunto, tem vontade de saber mais".

Fonte: elaborado pelas autoras com base na coleta de dados. 
As declarações destacadas no quadro 2, possibilitaram a constatação da presença de elementos que remetem ao discurso do movimento Fashion Revolution, representado pelos cards da Figura 1. Esses se mostram principalmente relacionados à importância do movimento, à revolução que ele propõe na mudança de atitude dos consumidores para um consumo mais consciente. Além disso, questões como preocupações ambientais e sociais são identificadas de maneira notável.

\section{CONSIDERAC̣ÕES FINAIS}

Com a realização da análise de conteúdo foi possível observar um padrão nos interesses e expectativas dos participantes com relação ao Fashion Revolution Day. De maneira geral, percebe-se a existência de uma expectativa positiva de mudança no consumo por meio das propostas e da influência do movimento. Os participantes, que já estão engajados, entendem a necessidade de assumir a responsabilidade pela mudança de atitude de consumo e, em consequência, pela produção mais sustentável na moda.

Atribuindo a si mesmos a responsabilidade frente à necessidade de mudanças no cenário, são motivados por um forte apelo ao consumo consciente e uma moda mais ambientalmente amigável e ética. Esta percepção é, potencialmente, uma razão para que o discurso de ativismo tenha sido constatado de maneira mais consistente de forma individual e com maior relevância em comparação à abordagem que exige transparência na indústria da moda.

Outro pressuposto passível de hipótese seria a característica comum a vários participantes em se apresentarem como pessoas e empresas envolvidas com moda sustentável, isto é, que já praticam em certo nível a transparência em seus processos. Desta forma, o parâmetro de transparência não foi considerado uma questão de maior relevância no discurso dos participantes.

Já em relação à importância do movimento Fashion Revolution, o evento demonstrou um crescimento desde a sua edição anterior, ocorrida em Porto Alegre, entre os dias 16 e 24 de abril de 2016, na Universidade Federal do Rio Grande do Sul - UFRGS. Neste ano, o movimento ocorreu em 80 países (FASHION REVOLUTION, 2016). Em 2017, o movimento abrangeu 90 países, demonstrando estar mais consolidado, disseminando com suas propostas os preceitos de uma indústria da moda mais sustentável e sensibilizar e conscientizar a sociedade na defesa da causa.

É esperado que os dados gerados na análise possam auxiliar na organização dos próximos eventos, com o objetivo de ampliar a repercussão do discurso do movimento no público participante. Atendendo, assim, aos seus 
interesses e expectativas, através da adesão de novos participantes ao evento, sejam consumidores ou empresas, abrangendo principalmente um público ainda distante do movimento.

\section{REFERÊNCIAS}

ALENCAR, José Luciano $S$. et al. Os efeitos socioambientais causados pelos resíduos sólidos das indústrias de confecções do polo de moda de MaringáPR. Revista Eletrônica em Gestão, Educação e Tecnologia Digital, Santa Maria, v. 19, n. 3, p. 478-504, set./dez. 2015.

ASSOCIAC̣ÃO BRASILEIRA DA INDÚSTRIA TÊXTIL E DE CONFECÇÃO ABIT. Perfil do setor. 2017a. Disponível em: <http://www.abit.org.br/cont/ perfil-do-setor>. Acesso em: 10 out. 2017.

ASSOCIAC̣ÃO BRASILEIRA DA INDÚSTRIA TÊXTIL E DE CONFECC̣ÃO ABIT. Setor têxtil e de confecção brasileiro fecha 2017 com crescimento. 2017b. Disponível em: <http://www.abit.org.br/noticias/setor-textil-e-deconfeccao-brasileiro-fecha-2017-com-crescimento>. Acesso em: 15 mar. 2018.

BARDIN, Laurence. Análise de conteúdo. São Paulo: Ed. 70, 2016.

BERLIM, Lilyan. Moda e sustentabilidade: uma reflexão necessária. São Paulo: Estação das Letras e Cores, 2012.

BRASIL. Resolução no 510, de 7 de abril de 2016. Dispõe sobre as normas aplicáveis a pesquisas em Ciências Humanas e Sociais cujos procedimentos metodológicos envolvam a utilização de dados diretamente obtidos com os participantes ou de informações identificáveis ou que possam acarretar riscos maiores do que os existentes na vida cotidiana, na forma definida nesta Resolução. Disponível em: <http://conselho.saude.gov.br/resolucoes/2016/ reso510.pdf>. Acesso em: 9 maio 2017. 
CAMARGO, Cariane W.; RÜTHSCHILLING, Evelise A. Procedimentos metodológicos para projeto de moda sustentável em ambiente acadêmico. Moda Palavra, Florianópolis, v. 9, n. 17, p. 299-312, 2016.

ELKINGTON, John. Partnerships from cannibals with forks: the triple bottom line of 21st-century business. Environmental Quality Management, Wheaton, v. 8, n. 1, p. 37-51, 1998.

ETHICAL FASHION FORUM. Defining ethical fashion. Disponível em: <https:// www.ethicalfashionforum.com/the-issues/ethical-fashion>. Acesso em: 20 jun. 2017.

FASHION REVOLUTION BRASIL. Portal do movimento fashion revolution Brasil. Disponível em: <http://fashionrevolution.org/country/brazil/>. Acesso em: 8 jun. 2017.

FASHION REVOLUTION. Fashion revolution week Porto Alegre. 2016. Disponível em: <https://www.fashionrevolution.org/event/fashion-revolutionday-porto-alegre-2/>. Acesso em: 30 mar. 2018.

FASHION REVOLUTION. Fashion transparency index. 2016. Disponível em: <http://fashionrevolution.org/wp-content/uploads/2016/04/FR_ FashionTransparencylndex.pdf>. Acesso em: 15 maio 2017.

FLETCHER, Kate; GROSE, Lynda. Moda \& sustentabilidade: design para mudança. São Paulo: SENAC, 2011.

FUAD-LUKE, Alastair. Design activism: beautiful strangeness for a sustainable world. New York: Routledge, 2013.

GWILT, Alison. Moda sustentável: um guia prático. São Paulo: G. Gili, 2014.

INSTITUTO AKATU. Consumidor, o poder da consciência. Disponível em: <https://www.akatu.org.br/wp-content/uploads/2017/04/ ConsumidoroPoderdaConsciencia.pdf>. Acesso em: 10 jun. 2017.

KAZAZIAN, Thierry. (Org.). Haverá a idade das coisas leves: design e desenvolvimento sustentável. São Paulo: SENAC, 2005.

MACHADO, Jorge A. S. et al. Ativismo em rede e conexões identitárias: novas perspectivas para os movimentos sociais. Sociologias, Porto Alegre, v. 9, n. 18, p. 248-285, 2007. 
MCKINSEY COMPANY. The state of fashion 2017. 2017. Disponível em: https://www.mckinsey.com/ /media/McKinsey/Industries/Retail/Our\%20 Insights/The\%20state\%20of\%20fashion/The-state-of-fashion-2017-McKBoF-report.ashx. Acesso em: 20 out. 2017.

NUNES, Rita C. de; ROCHA, Maria A. Transformações na concepção do valor de moda a partir da adoção de um estilo de vida simples. São Paulo: PPGCOM ESPM, 2015.

SACHS, Ignacy. Caminhos para o desenvolvimento sustentável. Rio de Janeiro: Garamond, 2002.

SALCEDO, Elena. Moda ética para um futuro sustentável. Barcelona: G. Gili, 2014.

SILVA, Mariane V.; CANDIDO, Douglas B. O verdadeiro preço de uma bagatela: os impactos do fast fashion pelas lentes de the true cost. In: CONGRESSO BRASILEIRO DE CIÊNCIAS DA COMUNICAÇÃO, 39., 2016, São Paulo. Anais eletrônicos... São Paulo: INTERCOM, 2016. Disponível em: <http://portalintercom.org.br/anais/nacional2016/resumos/R11-0604-1.pdf>. Acesso em: 20 mar. 2018.

UNIETHOS. Sustentabilidade e competitividade na cadeia da moda. 2013. Disponível em: <http://www.abit.org.br/conteudo/links/estudo_ sustentabilidade_uniethos.pdf $>$. Acesso em: 20 mar. 2018.

VALENTE, Fernando P. Indústria têxtil e de confecção mobilizada pelo desenvolvimento. In: DE CARLI, Ana Mery Sehbe; VENZON, Bernardete Lenita Susin (Org.). Moda, sustentabilidade e emergências. Caxias do Sul: Ed. EDUCS, 2012. 